\title{
PROCESSO DE DIFUSÃO E TQC
}

\author{
Nelson Yokoyama \\ PPGEP - Departamento de Engenharia de Produção -Universidade Federal de São Carlos \\ C.P. 676 - 13565-905 - São Carlos - SP; Fone: (0162) 74-8236/37/38; Fax: (0162) 71-2081
}

No momento em que assistimos em todo o país a uma disseminação em grande escala de conceitos rotulados de modelo japonês de gestão industrial (conceitos difundidos em nível global e aceitos como uma das poucas alternativas viáveis que se apresentam para uma melhor competitividade das empresas, em torno do binômio qualidadeprodutividade, legitimado que foi pelo desempenho da economia japonesa), procuramos através deste trabalho buscar uma melhor compreensão dos aspectos que envolvem um processo de difusão, seja de uma inovação tecnológica ou social, o que, para nós engenheiros, nem sempre ocorre de uma maneira lógica, possuindo uma racionalidade distinta daquela com a qual, pelas características de nossa formação, estamos acostumados a lidar (na maioria das vezes técnicas ou econômicas). Em particular, apresentaremos considerações a respeito do estágio atual de nossa pesquisa, que versará sobre o processo de difusão de uma metodologia específica, o TQC (Total Quality Control).

Palavras-chaves: processo de difusão, TQC, institucionalização.

\section{Introdução}

O conteúdo deste trabalho começou a ser delineado quando procurávamos dar prosseguimento a uma pesquisa que abordava a viabilidade da importação do sistema japonês de administração e de suas técnicas industriais. Naquela ocasião, levantamos alguns dados que, em princípio, contrariavam uma lógica mais imediata. Constatamos, pela análise de informações coletadas em uma publicação especializada em negócios (REVISTA EXAME, edição especial MAIORES e MELHORES, anos 1984 a 1992), que a participação das empresas de capital japonês no conjunto das quinhentas maiores empresas instaladas no Brasil era muito pequena (se comparada, por exemplo, à quantidade de empresas de capital norte-americano). As vinte maiores empresas japonesas atuavam preferencialmente em setores oligopolizados e, em alguns casos, poder-se-ia afirmar que detinham o monopólio (no caso das indústrias de motocicletas). No único setor mais concorrencial em que estavam presentes (eletroeletrônico) não tiveram um desempenho geral que pudesse ser considerado significativamente superior ao das empresas brasileiras ou de outras nacionalidades (sua evolução no quadro setorial deve ser creditada, principalmente, às associações com outras empresas e contratos de transferência de tecnologia). A única empresa que 
poderia servir de exemplo do modelo japonês seria a Honda (indústria de motocicletas). Nem a Toyota, reverenciada mundialmente pelo seu just-intime/kanban, serviria de referência, devido ao seu pequeno porte e pouco dinamismo, em relação ao desenvolvimento de seu mix de produtos.

Além disso, já tínhamos conhecimento de que as empresas japonesas nem sempre foram as primeiras, no Brasil, a incorporar os preceitos do modelo japonês de gestão da produção. Em nossa pesquisa inicial, a empresa estudada, considerada como modelo a ser seguido e destaque do ano pelo seu bom desempenho financeiro, implantou os Círculos de Controle de Qualidade tomando inicialmente o exemplo de sua implantação em uma empresa americana sediada no país.

Desta maneira, concluímos que as empresas japonesas instaladas no Brasil não poderiam ser consideradas como os principais agentes de difusão do modelo japonês (ou seja, não poderiam servir de exemplo próximo positivo para que outras empresas concorrentes ou similares praticassem o que em engenharia é conhecido por engenharia reversa). Como estaria ocorrendo este processo e quais seriam os agentes de difusão? Para tentar encontrar uma resposta mais plausível a estas indagações, iniciamos nosso trabalho por um aprendizado teórico a respeito do tema processo de difusão, tentando enquadrá-lo tanto em âmbito nacional como no de organizações e indivíduos. A seguir, procuramos descrever o percurso do TQC (concentramos os esforços numa única metodologia, para possibilitar uma análise mais profunda, e nesta, especificamente, porque consideramos que já está sendo utilizada em um período de tempo suficiente e, portanto, tem um histórico extenso e publicado), desde a sua origem até o estágio atual, localizando seus principais agentes difusores, as variações conceituais a que foi submetido e, finalmente, mediante as informações coletadas até o momento, mostrar o desenvolvimento do TQC no Brasil e definir linhas de pesquisa para o tema que ora apresentamos.

\section{Processo de difusão}

\subsection{Transferência de inovação}

HUMPHREY (1990), ao discutir a transferência do modelo japonês para o Brasil, constatou que, em uma situação de crise, o modelo estaria sendo apresentado como um remédio para tudo, e que existia uma tendência a apresentar este modelo como um pacote fechado, que deveria ser adotado integralmente. Isto resultaria na marginalização das questões de adoção seletiva ou adaptação das práticas japonesas. Além disso, o modelo estaria sendo apresentado como best way, o mais eficiente universalmente; desta forma, as adaptações seriam caracterizadas como second best way. O autor contesta estas noções, evidenciando a necessidade de adaptações. Neste mesmo texto, para reforçar sua argumentação, utiliza as palavras de FERRO (1989) proferidas quando da discussão do Toyotismo no Brasil, ressaltando a possibilidade de sua aplicação, a não existência de outra alternativa e a necessidade de um cuidado para não se introduzir somente algumas partes do modelo. Segundo FERRO (1989, p.16), para a extensão em que as partes deste modelo são interdependentes, deveriam ser 
introduzidas juntas. A questão fundamental seria a introdução de maneira crítica, adaptando-o às condições locais sem seguir receitas.

Estas duas correntes de pensamento, a primeira preocupando-se unicamente com o aspecto da competitividade, da face técnica do modelo, do best way, e a segunda, que enfoca o modelo como uma inovação técnica e organizacional, levando em conta aspectos como a cultura (as vertentes mais radicais chegando a desaconselhar a transferência do modelo, devido às condições peculiares da cultura japonesa, da qual seria fruto), encontraram ressonância tanto no mundo acadêmico quanto no empresarial, cada uma ganhando adeptos, em maior ou menor número, ao longo do tempo. Raciocinando unicamente em termos de cultura, não consideramos este fator como um obstáculo intransponível, pois, ratificando as idéias apresentadas por SATOSHI (1985), ela serviu no Japão como um fator de legitimação do statu quo, sendo utilizadas as mesmas características culturais para diferentes fins, ao longo do processo de industrialização daquele país.

Um refinamento destes conceitos pode ser encontrado no trabalho de COLE (1989), mais precisamente em seu estudo sobre as atividades de pequenos grupos, nas indústrias do Japão, Suécia e Estados Unidos. Cole (autor que utilizaremos como referência básica para nossa pesquisa) chega à conclusão de que cultura pode ser uma barreira, mas não necessariamente da forma como é comumente tratada. Referindo-se à resistência encontrada nos EUA na adoção destas atividades de pequenos grupos, baseadas em modelos suecos e japoneses, argumenta que a barreira cultural poderia estar presente, na verdade, na necessidade dos participantes destes grupos terem um senso de invenção local, seja no âmbito nacional, da empresa ou do local da fábrica e do serviço. Entendemos que, no caso americano, a situação é um pouco mais complexa, pois estaria presente um fenômeno que poderíamos caracterizar como xenofobia, motivada pela perda do senso nacional de serem os melhores do mundo. Continuando, afirma ser necessário reinventar a roda (Contrary to popular wisdom, there are times when it pays to reinvent the wheel! (COLE (1989, cap.7, p.117)). Fica claro, por meio desta proposição, que o modelo, ao ser transferido, precisa de uma recontextualização, ou seja, precisa ter um significado, uma identidade para seus usuários, de modo que estes acreditem na sua importância e se sintam motivados a adotar a inovação, tendo o senso de ter contribuído para a sua invenção. Para isto, deve-se utilizar know-how e recursos locais (em qualquer caso de transferência de inovação, seja ela tecnológica ou social). Não sem razão, as atividades de pequenos grupos (e programas de qualidade) tiveram um desenvolvimento diferenciado nos três países citados (com estágios evolutivos e desempenhos distintos).

\subsection{Institucionalização}

FLEURY \& SALERNO (1989), em estudo sobre os novos paradigmas de organização da produção, já chamavam a atenção, de certa forma, para a insuficiência de uma abordagem exclusivamente técnico-econômica. De acordo com estes autores, baseando-se em trabalho de PEREZ (1985), um processo de modernização envolveria também as características sócio-institucionais de um dado sistema social. Segundo 
eles, Perez "ao analisar os contornos da crise com que se defrontavam países e empresas, destacou que haveria uma defasagem (mismatch) entre as demandas do novo paradigma técnico-econômico identificado e o paradigma sócio-institucional sobre o qual estavam estruturadas as sociedades industriais" (FLEURY \& SALERNO (1989, p.3)).

"The biggest argument for computers was because your competitor had one..." (COLE (1989, p.108)). Esta frase expõe a lógica que permeia em maior ou menor grau a difusão da implantação de computadores pelas organizações, baseada no senso comum de best practice (COLE (1989, p.108)). Este senso comum pode ser notado no processo de difusão de quaisquer outras inovações, sejam elas tecnológicas ou sociais. A partir das argumentações iniciais de Fleury e Salerno, e do exemplo fornecido por Cole, pretendemos detalhar algumas características inerentes a um processo de difusão de novas idéias, tanto em nível de organizações como de indivíduos, abordando questões como isomorfismo, papel dos atores sociais e a importância das crenças no desenrolar desse processo.

POWEL \& DI MAGGIO (1991), argumentam que mudanças organizacionais (citando exemplos de burocratização e racionalização) ocorreriam como resultado de processos que tornariam as organizações mais similares, sem necessariamente torná-las mais eficientes e que, "the concept that best captures the process of homogenization is isomorphism" (p.66). Evidenciam, também, a importância dos decision makers dentro de uma organização, para que este processo de mudança se efetue. Apresentam dois tipos clássicos de isomorfismo: competitivo e institucional. O primeiro, sob uma ótica mais racional, estaria voltado para a competição de mercado, sendo mais relevante num ambiente de mercado aberto e concorrencial. Explicaria parte do processo de burocratização que WEBER (1974, cap.8, p.229-282) observou, podendo ser aplicado a um estágio inicial de inovação. $\mathrm{O}$ segundo, seria o mais adequado para explicar o mundo moderno das organizações, em que estas mesmas organizações não competiriam apenas por clientes e recursos, mas também por poder político e legitimidade institucional, tanto no campo social como no econômico. Finalmente, identificam três mecanismos por meio dos quais ocorreria a mudança isomórfica institucional: coercitivo, mimético e normativo. O primeiro, baseado na influência política e no problema de legitimação; o segundo, nas respostas padronizadas em meio a incertezas, e o terceiro, associado com profissionalização.

MEYER \& ROWAN (1991), em estudo sobre a institucionalização de organizações, fornecem algumas hipóteses bastante instigantes. De acordo com estes autores, independentemente de uma possível eficiência, a utilização de técnicas institucionalizadas rotularia uma organização como sendo apropriada, racional e moderna. Essa utilização seria uma demonstração de responsabilidade, evitando críticas a uma possível atitude de negligência. Como conseqüência, empréstimos seriam mais facilmente obtidos, ter-se-ia um crédito maior junto a investidores, clientes e até mesmo dos integrantes da própria organização. Tudo isso ocorreria dentro de um comportamento coletivo que poderíamos chamar de boa fé, que poderia, per se, acabar levando à concretização dos resultados almejados, ou seja, fazendo a verdade acontecer. 
FLIGSTEIN (1991), dando prosseguimento ao trabalho de CHANDLER (1990) sobre as transformações estruturais da indústria americana ao longo do tempo, afirma que as mudanças organizacionais seriam efeito de um pequeno leque de circunstâncias. O momento ideal para tais tipos de mudança seria o estágio inicial de uma estruturação organizacional. Do contrário (se a organização já se apresentar num estágio de maturidade), estas mudanças provavelmente só ocorreriam sob o impacto de medidas de choque, resultantes de ações do Estado, de outras organizações ou de condições macroeconômicas. Num momento de instabilidade, as mudanças ocorreriam como resultado de três fatores: primeiro, o poder dos atores (com uma nova percepção da situação) para agir nas organizações já existentes; segundo, organizações que passam a existir com as novas estratégias; e terceiro, forças de institucionalização em áreas organizacionais em que os atores acabariam por imitar a conduta existente em organizações-padrão.

Ao falarmos de atores, fica claro que entendemos uma empresa ou organização como uma estrutura humana, além de técnica. RILEY \& RILEY (1971, p.118-154) citam uma investigação na Western Eletric para ilustrar a importância das relações informais dentro de uma estrutura social mais ampla. Enfatizam a existência de uma organização humana, além da técnica, que estaria subdividida em organizações formais e informais: "as observações de pesquisa indicam os processos através dos quais os grupos informais de amigos e colegas funcionam, tanto para sustentar como para afastar do objetivo da organização formal, que é a produtividade eficiente". Desta forma, não podemos nos furtar a sugerir que as disputas de poder que ocorrem entre as organizações também têm uma correspondência no interior das organizações e, tomando por empréstimo as palavras de Riley \& Riley, nem sempre norteadas pelo objetivo final das organizações, a produtividade eficiente. Assim, estas inovações instrumentalizariam o conflito por poder e espaço dentro da organização, em âmbito de indivíduos e grupos, como, por exemplo, o conflito de gerações entre os integrantes do quadro de funcionários e o conflito entre os diversos setores em que uma organização está dividida.

Pesquisadores do tema Cultura Organizacional consideram saudável a existência de correntes de pensamento heterogêneas dentro de uma organização, as quais denominam de sub-culturas (cuidando para diferenciá-la de uma contracultura, geralmente considerada maléfica), alegando que este fator tornaria a organização mais dinâmica e, por conseguinte, mais competitiva. Nessa mesma linha de estudo, KOTTER \& HESKETT (1992) declaram que somente uma empresa com uma cultura organizacional que se antecipe e se adapte às mudanças ambientais pode almejar, com um mínimo de segurança, um desempenho superior durante longo período de tempo. Os conceitos de Cultura Organizacional podem ser associados com os conceitos de crença pois, de acordo com Schein, temos que: "Cultura organizacional é o padrão de premissas básicas que um determinado grupo inventou, descobriu ou desenvolveu no processo de aprender a resolver seus problemas de adaptação externa e de integração interna e que funcionaram bem o suficiente a ponto de serem consideradas válidas e, portanto, de serem ensinadas a novos membros do grupo como a maneira correta de perceber, pensar e sentir com relação a esses 
problemas" (p.56). FLEURY (1991, p.249), acrescenta à definição de Schein o conceito de poder, ao afirmar que estas mesmas premissas também "ocultam e instrumentalizam as relações de poder".

Em relação à crença na best practice, algumas proposições levantadas por COHEN (1968) são muito úteis para uma melhor compreensão. Assim, novas crenças exigem um grande esforço para que cheguem a ser habituais e consideradas mais satisfatórias que as anteriores, pois elas devem vencer barreiras (como hábito e inércia) que fazem com que seja mais fácil para os indivíduos continuar acreditando em idéias em que sempre acreditaram. Uma das formas para que uma crença se institucionalize é o apelo à autoridade, a uma fonte respeitada, no afã de se buscar um apoio para as opiniões defendidas. Esta autoridade, imbuída de uma suposta infalibilidade e indubitabilidade, é muito utilizada para eliminar opiniões divergentes, conformando-as à crença vigente. Para que novas idéias se tornem uma crença, elas devem atingir um grau de consenso em que são vistas como evidentes em si mesmas, não necessitando ser questionadas e soando até absurda tal atitude. Cohen afirma que estas evidências freqüentemente são funções das modas dos conhecimentos anteriores e coloca como exemplo a antiga proposição em que todos os grandes astrônomos acreditavam, incluindo Copérnico, segundo a qual seria evidente que as órbitas dos planetas deviam ser circulares, ou uma proposição mais atual, que muitos ainda consideram evidente por si mesma: o todo é maior que qualquer das partes. Podemos ainda colocar outro exemplo, que é a questão da privatização da economia (idéia bastante difundida no Brasil e no mundo): alguém, em sã consciência e sem temor de receber uma saraivada de críticas, seria capaz de expor em público as incongruências existentes no conceito difundido de que privatização e desempenho caminham necessariamente juntos? Alguém já teria ouvido através dos meios de comunicação um relato de experiência negativa de privatização? Questiona-se a melhor maneira de fazer a privatização, não a sua validade universal.

\subsection{Meios de comunicação}

Neste capítulo, completaremos a nossa formulação teórica, apresentando considerações a respeito do tema comunicação, enfatizando o papel dos indivíduos formadores de opinião e dos meios editoriais, tentando, dessa forma, demonstrar a importância desses dois aspectos em um processo de difusão de novas idéias.

KATZ (1957), utiliza um estudo de Lazarsfeld que, em uma análise do processo de tomada de decisão no transcurso de uma campanha eleitoral, formulou a hipótese da comunicação em dois tempos: as informações difundidas pelos meios de comunicação se transmitiriam menos diretamente do que se supunha. Sua influência chegaria primeiro aos indivíduos formadores de opinião que, por sua vez, transmitiriam a mensagem, por meio de uma linguagem própria, para os indivíduos componentes do setor em que exercessem a sua influência. Complementando, Katz afirma que estes indivíduos, receptores finais da informação, dentro de um setor específico, apresentam uma grande homogeneidade em suas opiniões; que o papel dos meios de comunicação de massa é complexo, podendo ir desde a informação até a 
legitimação de opiniões; que a autoridade destes formadores (ou líderes) de opinião é limitada a um determinado campo e eles têm características semelhantes às dos indivíduos que influenciam, distinguindo-se por suas qualidades (como competência) e posição social; e que estes líderes estão, por sua vez, mais expostos à ação dos meios de comunicação de massa e são mais sensíveis à sua influência. Finalmente, afirma que não se pode omitir a existência de líderes com maior autoridade, que acabariam por influenciar líderes setoriais.

Este apelo à autoridade, por parte dos indivíduos considerados receptores finais da informação, ratifica a proposição de Cohen segundo a qual esta atitude refletiria um comportamento comum de se invocar uma força externa (investida de infalibilidade e indubitabilidade) para sancionar suas decisões e até para ser utilizada quando não se dispõe de tempo ou preparação para resolver algum tipo de problema.

O papel dos meios de comunicação suscita muitas questões. Numa análise comedida, se imaginarmos uma publicação em termos de um produto de uma empresa, ela deveria se adequar às exigências de seus potenciais consumidores (por uma questão de sobrevivência). Desta forma, o seu conteúdo editorial deveria ser coerente com a visão de seus leitores. Mesmo que ela tivesse uma postura mais crítica, não poderia se distanciar muito da realidade destes mesmos leitores, ou seja, as matérias escolhidas deveriam ser aquelas que os leitores buscassem ler e que passassem uma visão próxima à do leitor médio. Mesmo que institucionalmente a publicação se tornasse uma leitura obrigatória para determinados setores, sua atuação dificilmente poderia escapar de ser classificada de legitimadora de opiniões, embora provavelmente preferisse ser rotulada de informativa e com independência editorial.

Numa crítica mais contundente, ADORNO (1971, p.287-295) declara que: "O consumidor não é rei, como a indústria cultural gostaria de fazer crer, ele não é o sujeito dessa indústria, mas seu objeto"; "As mercadorias culturais da indústria se orientam (...) segundo o princípio de sua comercialização", e "As idéias de ordem que ela inculca são sempre as do statu quo". Da mesma forma que se pode fazer uma analogia da indústria cultural com os meios de comunicação em geral, pode-se fazer uma analogia da propaganda com os meios de comunicação. BARAN (1971, p.210) afirma: "Uma das funções da propaganda é o reforço dos desejos e inclinações sociais (...) dos consumidores ".

\subsection{Outras considerações}

A técnica, em si, pode ser considerada neutra, mas como não podemos dissociá-la de sua utilização, temos que duvidar da pretensa neutralidade com que muitas técnicas nos são apresentadas. Além de instrumentalizar as relações e conflitos de poder (anteriormente citado), ela pode servir para respaldar decisões totalmente antagônicas. Como exemplo, temos o caso apresentado por GRUN (1985) sobre automação bancária, no qual se concluiu que a automação poderia ser utilizada tanto para centralizar como para descentralizar operações e decisões. Outro exemplo típico a respeito de automação foi oferecido por SILVA (1991), em seu estudo sobre a indústria automobilística, no qual relatou que, para o processo de fabricação de um 
mesmo modelo de automóvel, a fábrica instalada no Brasil não teve sua linha de produção automatizada, ao contrário do que ocorreu com uma fábrica instalada na Europa. Em ambos os casos, a qualidade serviu como pretexto, segundo a autora, para justificar a opção pela automação e pela não automação.

Outro fator importante é a capacidade de uma técnica em renovar-se ao longo do tempo, ou seja, a sua elasticidade para servir como instrumento para diferentes ações em contextos distintos (em espaço e tempo). Esta noção de renovação está associada à tese formulada por Cole sobre a necessidade de se reinventar a roda e será utilizada para tentarmos descrever e compreender, da melhor maneira possível, a trajetória percorrida pelo TQC.

\section{TQC (Total Quality Control)}

\subsection{Considerações iniciais}

A busca de uma definição para o TQC pode resultar em uma tarefa inglória (a literatura oferece uma variedade extensa de conceitos em torno desta sigla) se não estivermos atentos ao seu caráter polissêmico (que é o tema central do trabalho que desenvolveremos a partir deste ensaio), mutante em distintos períodos de tempo e espaço geográfico. Um bom resumo destas várias facetas do TQC pode ser encontrado em ALVES et al. (1993, p.74). De acordo com estes autores:

"Assim como não existe um consenso sobre o que é qualidade, também não existe uma definição única e estruturada sobre TQC. Desde as mensagens iniciais sobre a necessidade de gestão e melhoria contínua da qualidade de produtos e serviços, emitidas na década de 50 por Deming e Juran, passando pelo trabalho de Feigenbaum, que foi o pioneiro no uso do termo Total Quality Control em seu livro publicado em 1961, passando também pelo conceito japonês de Company-Wide Quality Control até chegar ao que hoje se chama de TQC no Japão e de TQM - Total Quality Management (ou de TQ - Total Quality) nos EUA e Europa, um longo caminho foi percorrido".

"Desta evolução resultou um emaranhado de publicações sobre o tema, onde em cada uma das quais, sob uma mesma denominação genérica (TQC ou TQM), se abordam questões específicas de diferentes níveis e conteúdo, e que raramente são devidamente posicionadas em relação ao todo, tais como: conceitos e princípios, filosofia de gerenciamento, técnicas, metodologias, processos de aperfeiçoamento, etc".

"Assim, nos meios de difusão do TQC, tais como publicações, empresas de consultoria, associações de profissionais, etc, o mesmo é apresentado às vezes como um sistema de qualidade (FEIGENBAUM (1983)), às vezes como uma filosofia de gerenciamento ( KANO (1990); ISHIKAWA (1981)) e ainda como um processo de aperfeiçoamento contínuo do desempenho".

Os princípios de qualidade preconizados por autores como Deming e Juran (citados anteriormente por Alves et al.) podem ser encontrados em DEMING (1982), JURAN $(1974,1986,1991)$ e JURAN \& GRINA (1970). 
Apenas como referência, apresentaremos a definição de CIAMPA (1992), que visualiza o TQ (nomenclatura americana para TQC) como um novo conceito de gerenciamento, fazendo uma combinação equilibrada do lado técnico e organizacional

(uma abordagem bem aceita atualmente). Segundo Ciampa, existiriam três maneiras de se definir Qualidade Total: a primeira, a partir da uniformidade de princípios, que seria a dedicação total aos clientes, indo de encontro às suas necessidades e até excedendo às suas expectativas; a segunda, a partir dos resultados, que seria aumentar a fidelidade dos clientes, minimizar tempos e custos, criar um ambiente que incentive team work, enriqueça o trabalho e crie uma ética generalizada de melhoramento contínuo e, finalmente a terceira, a partir das ferramentas e técnicas como Controle de Qualidade, Qualidade Assegurada, Engenharia de Confiabilidade, Just-in-Time, Desenvolvimento Organizacional e Liderança. Podemos detalhar um pouco mais estas ferramentas. Assim, relacionamos algumas ferramentas mais específicas: As Sete Ferramentas da Estatística, As Sete Novas Ferramentas da Administração, Controle Estatístico de Processo, Projeto de Experimentos, Desdobramento da Função Qualidade, Técnicas de Confiabilidade, Kanban, Células de Manufatura, Redução de Set-Up, Análise do Fluxo do Valor-Adicionado, Fornecedores Just-in-Time, Programas Motivacionais e Participativos, CCQ, Atividades de Pequenos Grupos, Kaizen, Reengenharia, etc. De um modo ainda mais sucinto, CIAMPA (1992, p.41) define: "Qualidade Total descreve o estado de uma organização na qual todas as atividades e todas as funções são escolhidas e levadas adiante como um meio para se ir de encontro às exigências dos clientes externos, reduzindo tempo e custos internos e melhorando o clima do local de trabalho".

\subsection{Histórico}

Desde que se iniciou o processo de industrialização, os modelos de práticas industriais difundiram-se a partir da Europa, depois da América do Norte e, mais recentemente, do Extremo Oriente. No caso japonês, a instituição que tem sido considerada como um dos principais agentes difusores na área da qualidade é a JUSE (Japanese Union of Scientists and Engineers), que focalizou seus esforços na introdução de práticas modernas de controle de qualidade e, mais tarde, em CCQ (Círculos de Controle de Qualidade). Os historiadores enfatizam a colaboração, a partir da década de 50, de consultores como Deming (no controle estatístico da produção) e Juran (com uma nova orientação para o controle da qualidade, posicionando-o como parte integrante da função de gerenciamento e praticado por toda a organização), além da utilização da teoria de Feigenbaum (com ênfase no controle total da qualidade) para a difusão dos princípios de qualidade pelas empresas japonesas.

COLE (1989) relata que estas idéias tiveram um rápido desenvolvimento no Japão de meados da década de 50 até o início dos anos 60, mas sofrendo uma reinterpretação pelas empresas que as adotaram. O fator mais importante seria que: "Characteristically, the Japanese borrowed many of these ideas and extended their aplication to blue-collar employes" (p.99). Ainda segundo Cole, ao contrário do que 
ocorreu no Japão, onde a alta direção das empresas se envolveu com estas novas idéias através de um intercâmbio intenso com a JUSE (a qual, no início dos anos 60 já tinha adquirido uma considerável reputação local como difusora de informações sobre desenvolvimento da qualidade), o TQC percorreu um caminho bastante distinto nos EUA. As congêneres americanas da JUSE, a ASQC (American Society for Quality Control, fundada em 1946) e, mais tarde, a IAQC (International Association of Quality Circles), acabaram por se tornar entidades de classe, gerando um comportamento que poderíamos chamar de corporativista. Ou seja, estas novas idéias instrumentalizaram as relações de poder de uma categoria profissional (basicamente a dos engenheiros), permanecendo nas mãos de especialistas e consultores. Dessa maneira, a difusão destas idéias nos EUA teve um caráter bastante restrito. Da mesma forma, as atividades de pequenos grupos (estudadas por Cole) também se mostraram distintas nos dois países; enquanto no Japão elas se orientaram para a resolução de problemas específicos, nos EUA elas existiram per se, mais afinadas com os princípios de QWL (Quality-of-Work-Life).

Atualmente, no Japão, o TQC é definido como um sub-grupo do CWQC (Company Wide Quality Control). Segundo ISHIKAWA (1986), TQC é o sistema para integração da tecnologia da qualidade em vários departamentos funcionais (engenharia, produção, vendas e serviços), para obter a satisfação do consumidor, e CWQC, como algo mais abrangente, para proporcionar bens e produtos de baixo custo, dividindo o benefício entre os consumidores, empregados e fornecedores, enquanto melhora a qualidade de vida das pessoas. Nos EUA, o TQC está mais voltado para a qualidade de produtos e processos, o que, na percepção de muitos estudiosos, configuraria um estágio mais inicial do TQC. As publicações americanas sobre TQC, como SULLIVAN (1986) e GARVIN (1988), geralmente enfatizam tecnologia, controle de qualidade e de processo, qualidade em torno de especificações e expectativas dos consumidores. Como exemplo do que ocorre na prática, uma pesquisa de DE MEYER et al. (1989) junto a empresas européias, americanas e japonesas, em torno dos planos de ação considerados mais importantes por parte destas empresas, concluiu que, no período compreendido entre 1985 e 1989, esses planos tiveram a seguinte evolução: a principal estratégia das empresas européias passou de sistemas integrados de informação da produção (em 1985) para motivação do trabalho (em 1989); nos EUA passou-se dos sistemas de controle de produção e estoque para o controle estatístico de processo e, no Japão, a principal preocupação continuou sendo o sistema flexível de manufatura. Desta maneira, segundo muitos autores, as empresas japonesas estariam num patamar mais avançado, do TQC e do sistema produtivo como um todo, que o das empresas americanas e européias, simbolizando a modernidade e legitimando novos paradigmas, como das empresas consideradas pós-industriais. DOLL \& VONDEREMBSE (1991), citam algumas das características presentes na empresa pós-industrial: orientação para o cliente, desenvolvimento de produtos, concentração de capital, flexibilidade, uso de informações e trabalho intelectual, auto organização e auto direção dos grupos de trabalho, sistemas de controle de desempenho múltiplos e globais, sistemas de informações formais e informais, cooperação e interação com o mercado. 
CUNHA (1990) e MARTINS (1992), em estudos sobre o tema processo de difusão, chegaram a conclusões similares e que podem ser utilizadas também para o TQC: as estratégias e interpretações em torno do tema qualidade (de experts como Deming, Juran, Crosby e outros) se diferenciariam mais na apresentação do que nos objetivos propostos (como conseqüência das diferenças de formação acadêmica: estatísticos, administradores, engenheiros, etc). Segundo Cunha e Martins, as propostas de gestão da qualidade convergiriam, de um modo geral, para o estágio de TQC.

Entendemos que os princípios do TQC mantiveram-se constantes ao longo do tempo; foram as suas metodologias (técnicas ou organizacionais) e as ferramentas específicas destas metodologias que sofreram reinterpretações, obtendo um grau maior de desenvolvimento e legitimidade, conforme o local, a ocasião e a atuação dos atores sociais (agentes de difusão) envolvidos. Afinal, segundo o próprio ISHIKAWA (1986, p.7): "TQC nada mais é do que a realização do óbvio".

\subsection{Caso Brasil}

No quadro mais geral de modelos, VARGAS (1985, p.164), relata que, no Brasil, o IDORT (Instituto de Organização Racional do Trabalho) foi fundado em 1931, nos moldes da Taylor Society americana, e sua diretoria era formada por lideranças empresariais do Estado de São Paulo. Ainda segundo Vargas, o IDORT teve um importante papel na difusão dos métodos americanos, principalmente nas décadas de 30 e 40. Para muitos autores, o modelo japonês aterrisou no Brasil antes mesmo que nos EUA, mas a sua difusão tomou impulso somente a partir da década de 80. MARTINS (1992), ressalta que a década de oitenta representou um divisor de águas para as empresas industriais brasileiras, que tiveram que voltar sua atenção para o mercado externo. Dessa forma, no intuito de atender às pressões normativas (padrões de qualidade superiores no mercado externo), as empresas brasileiras (pricipalmente as pertencentes aos setores mais dinâmicos do parque industrial) começaram a tomar contato com novos conceitos como o TQC.

CUNHA (1990) e MARTINS (1992) descrevem o que consideraram como sendo os principais canais de difusão das estratégias, conceitos e métodos dos teóricos da qualidade no Brasil: associações de profissionais da área de qualidade, universidades, empresas de consultoria e consultores independentes, empresas estatais e privadas, orgãos governamentais de regulamentação, publicações especializadas, etc. Detalham o histórico da ABCQ (Associação Brasileira de Controle da Qualidade) por causa de seu pioneirismo na área, mas limitam a importância de seu papel de agente difusor do TQC na medida em que observam a sua trajetória: a associação teria se tornado, a exemplo da ASQC, à qual é filiada desde 1986, em uma típica associação profissional, com a maioria de seus membros pertencendo à categoria individual (geralmente de nível gerencial médio), e não à de empresas.

O poder público entrou em cena com o lançamento, em 1990, do PBQP (Programa Brasileiro de Qualidade e Produtividade). De acordo com MARTINS (1992, p.5): "O programa é resultado de um somatório de subprogramas e projetos. 
Sua execução, fortemente descentralizada, tem no empresariado seu maior agente. Ao governo cabem os papéis de articulador institucional e provedor de infra-estrutura tecnológica". Junto com o PBQP, entra em cena a Fundação Christiano Ottoni (sediada no estado de Minas Gerais e ligada à Universidade Federal de Minas Gerais) como a mais nova pretendente ao papel de principal agente difusor de práticas japonesas, concorrendo com outras entidades como a ABCQ e a Fundação Vanzolini (ligada à Escola Politécnica-USP).

Quanto ao estágio atual do TQC no Brasil, podemos citar um estudo que, mesmo não sendo especificamente sobre este tema, fornece informações que consideramos bastante úteis. CARVALHO (1992) declara que:

"A baixa prioridade atribuída historicamente à capacitação tecnológica no Brasil, aliada aos efeitos da crise sobre o investimento, que terminaram por retardar o processo de modernização e a difusão de novas tecnologias e técnicas organizacionais, são os determinantes diretos da relativa permanência de trabalhos convencionais, assentados sobre o princípio taylorista da separação entre o saber e o fazer" (p.25).

Continuando:

"Os mesmos fatores que retardam a difusão de novos equipamentos de produção atuam no sentido de atrasar a incorporação dos novos métodos (japoneses) de organização da produção voltados para o aumento da qualidade e produtividade. Nesta área, a identificação da difusão é mais nebulosa, à medida que as inovações organizacionais são menos tangíveis (que um equipamento, por exemplo), tornando difícil separar o discurso empresarial da verdadeira prática. As evidências têm que se basear em trabalhosos estudos de caso, sendo discutível a validade de coleta de estatísticas sobre modificações organizacionais."

"Há muito discurso e debate, nos meios empresariais e governamentais, sobre a necessidade de as empresas brasileiras adotarem novos métodos de Qualidade e Produtividade. O governo Collor chegou à implentação de um programa formal com este objetivo, considerado um dos esteios de sua política industrial. Proliferam artigos de consultores, seminários, entrevistas de empresários e gerentes sobre o assunto."

"O grau de difusão e a natureza das mudanças organizacionais introduzidas no Brasil, no entanto, parecem estar aquém da propaganda. Uma criteriosa pesquisa encomendada pelo IPEA, com patrocínio do Banco Mundial (HUMPRHEY \& FLEURY (1992)), e que se concentrou numa amostra de empresas que estavam introduzindo novos métodos e técnicas (TQC, JIT, TPM, etc.) levou às seguintes conclusões:

- existe, de fato, um reduzido número de empresas no Brasil que estão avançadas na introdução dos novos métodos de Q \& P; direção;

- a imensa maioria das empresas industriais sequer iniciou esforços nessa

- o ritmo de difusão é lento e tem sido sujeito a retrocessos."

"HUMPRHEY \& FLEURY (1992) chamam a atenção para o fator que poderia ser identificado como o principal obstáculo à difusão dos novos métodos de Qualidade e Produtividade: "a amplitude e a profundidade das mudanças exigidas por tais programas". Em condições de retração de investimento, eu acrescentaria, é pouco 
factível (embora não impossível) esperar mudanças em profundidade" (p.30-31).

Em relação ao tema práticas japonesas, pode-se dizer que elas começaram a ser difundidas pelo país a partir de técnicas como o CCQ (apresentada por consultores como uma verdadeira mina de ouro a empresários historicamente rotulados como conservadores: uma técnica que envolveria baixo investimento e alto retorno financeiro, sem a necessidade de alterar a estrutura organizacional da empresa). Neste momento, estamos presenciando a fase Just-In-Time (em nome de um maior sincronismo do processo produtivo) e o surgimento de discursos em favor de técnicas como QFD (Desdobramento da Função Qualidade - metodologia que procura transformar os requisitos dos consumidores em especificações técnicas para a empresa) e Reengenharia (como uma resposta aos críticos que acusam o TQC de oferecer apenas um desenvolvimento incremental, propondo mudanças mais drásticas através de uma redefinição de conceitos, funções e estruturas em uma empresa). Porém, nem sempre estas técnicas foram apresentadas como ferramentas de um programa maior, como o TQC (em geral, o TQC continua sendo associado unicamente à área de processo produtivo, sendo que uma das ferramentas mais difundidas atualmente é o CEP (Controle Estatístico de Processo)); em algumas ocasiões, foram apresentadas como ferramentas isoladas e, em outras, como sub-itens de programas distintos ao TQC. Mesmo o TQC, quando assim apresentado, aparentemente revelou diversas interpretações ao longo do tempo (nota-se também, a exemplo do que ocorreu nos EUA, uma tendência de desvinculá-lo de sua origem japonesa). A propagação do modelo japonês via EUA poderia ser justificada, mediante de uma análise inicial, pelo fato de os grandes teóricos de escolas de administração serem americanos, a exemplo das maiores empresas mundiais, e pelo enorme potencial do mercado editorial e de consultoria desse país.

\section{Considerações Finais}

Tentamos, através desta revisão bibliográfica parcial, oferecer um quadro geral dos aspectos que incidem sobre o processo de difusão de uma inovação, seja ela de natureza tecnológica ou organizacional, e da difusão da metodologia TQC (enquanto parte integrante de práticas rotuladas de japonesas) no mundo e no Brasil.

Feito isto, reiteramos a linha de ação que irá direcionar a nossa pesquisa em torno do caso brasileiro: estudar as várias interpretações a que foi submetida a metodologia TQC, através da retórica utilizada pelos meios editoriais (cuja importância em um processo de difusão pode ser avaliada pelo conteúdo do capítulo referente aos meios de comunicação) e, dentro do possível, identificar e medir a participação dos agentes responsáveis por este processo de renovação do TQC. Desta forma, a metodologia da pesquisa de campo será baseada, inicialmente, em levantamento de dados junto a revistas e jornais especializados em negócios, e nas publicações das principais editoras de livros técnicos. A coleta de dados basear-se-á na literatura publicada no período compreendido entre 1984 e 1993. Uma vez realizada a análise desses dados, e a partir de algumas considerações iniciais, procuraremos investigar mais detidamente as diversas articulações e a competição entre grupos de 
agentes e instituições (identificados no rastreamento inicial) que deram vida à difusão do TQC na segunda metade dos anos oitenta no Brasil.

\section{Refrências Bibliográficas:}

ADORNO, T.W.: "A indústria cultural". In: COHN, G.: Comunicação e indústria cultural. p.287-295, Companhia Editora Nacional e ED-USP, São Paulo, 1971.

ALVES FILHO, A.G.; MARTINS, M.F.; NOGUEIRA, E.; TOLEDO, J.C.: "Administração estratégica da produção e controle da qualidade total: uma comparação". In: Cadernos DEP (Cadernos de Engenharia de Produção). ano X, n.20. p.69-81, DEP-UFSCar, São Carlos, 1993.

BARAN, P.A. \& SWEEZY, P.M.: "Teses sobre a propaganda". In: COHN, G.: Comunicação e indústria cultural. p.205-214, Companhia Editora Nacional e Editora da USP, São Paulo,1971.

BERELSON, B.; GAUDET, H.; LAZARSFELD, P.: El pueblo elige. Cómo decide el pueblo en una campaña electoral. Ediciones Tres, Buenos Aires.

CARVALHO, R.Q.: "Projeto de primeiro mundo, conhecimento e trabalho de terceiro?". Paper apresentado no XVI encontro anual da ANPOCS, Caxambú, 1992.

CHANDLER JR, A.D.: "The emergence of managerial capitalism". In: ZUKIN, A. \& DIMAGGIO, P.J.: Structures of capital: the social organization of the economy. Cambridge University Press, 1990.

CIAMPA, D.: Total Quality. Addison-Wesley, 1992.

COHEN, M. \& NAGEL, E.: Introdución a la lógica y al método científico. Amorrortu Editores, Buenos Aires, 1968.

COLE, R.E.: Strategies for learning: small-group activities in American, Japanese, and Swedish industry. University of California Press, Berkeley, 1989.

CUNHA, L.G.Z.: Caracterização e análise do processo e dos agentes difusores da gestão da qualidade industrial no Brasil. DEP-UFSCar, São Carlos, 1990.

DE MEYER, A.: "Flexibility: the next competitive battle the manufacturing futures survey". In: Strategic Management Journal. vol.10, p.135-144, 1989.

DEMING, W.E.: Quality, productivity, and competitive position. Massachusetts Institute of Technollogy, 1982.

DOLL, W.J. \& VONDEREMBSE, M.A.: "The evolution of manufacturing systems: toward the post-industrial enterprise". In: International Journal of Management Science. v.19, n.5, 1991.

FERRO, J.R.: Aprendendo com o Sistema de Produção Toyota: lições para o Brasil. São Paulo, 1989, (mimeo).

FLEURY, A. \& HUMPHREY, J.: "Recursos humanos e a difusão e adaptação de novos métodos para a qualidade no Brasil". Paper apresentado no Seminário internacional novas formas de gestão para a qualidade e produtividade. IPEA, Brasília, maio de 1992. 
FLEURY, A. \& SALERNO, M.: "Condicionantes e indutores de modernização industrial no Brasil". Paper preparado para o seminário internacional padrões tecnológicos e processos de trabalho: comparações internacionais. DEP Poli USP, São Paulo, maio de 1989.

FLEURY, M.T.: "Cultura de empresa e novas formas de gestão do trabalho". In: Ciências Sociais Hoje. p.245-261, 1991.

FLIGSTEIN, N.: "The structural transformation of American industry: an institutional account of the causes of diversification in the largest firms, 1919-1979". In: POWEL, W. W. \& DI MAGGIO, P. J.: The new institutionalism in organizational analysis. University of Chicago Press, 1991.

GARVIN, D.A.: Managing quality. Free Press, NY, 1988.

GRUN, R.: A produção de uma empresa moderna: os bancários e a automação. Dissertação de Mestrado, PUC-SP, São Paulo, 1985.

HUMPHREY, J.: "Adapting the "Japanese Model" to Brazil". Paper apresentado na conferência "Autour du Modèle Japonais", Paris, 1990.

ISHIKAWA, K.: TQC - Total Quality Control: estratégia e administração da qualidade. IMC, São Paulo,1986.

JURAN, J.M.: Quality control handbook. McGraw-Hill, NY,1974.

JURAN, J.M.: Planning for quality. Juran Institute Inc., Wilton, CT, USA,1986.

JURAN, J.M.: Controle da qualidade. McGraw-Hill/Makron, São Paulo,1991.

JURAN, J.M. \& GRYNA, F.M.: Quality planning and analysis. McGraw-Hill, NY, 1974.

KATZ, E.: "The two-step flow of communication: an up-to-date report on an hypothesis". In: BOURDIEU, P.; CHAMBOREDON, J. C.; PASSERON, J. C.: El oficio de sociólogo: presupuestos epistemológicos. p.224-231, Siglo XXI Editores S.A. de C.V., México,1987.

KOTTER, J. \& HESKETT, J.: Corporate culture and performance. Free Press, NY, 1992.

MARTINS, M.: Criação e difusão de novas tecnologias e padrões organizacionais. DEP-UFSCar, São Carlos,1992.

MELHORES E MAIORES. In: Revista Exame. Editora Abril, São Paulo, 1984 a 1992.

MEYER, J.W. \& ROWAN, B.: "Institutionalized organizations: formal structure as myth and ceremony". In: POWELL, W.W. \& DI MAGGIO, P. J.: The new institutionalism in organizational analysis. p.41-62,University of Chicago Press, 1991.

PEREZ, C.: "Microeletronics, long waves, and world structural change: new perspectives for developing countries". In: World Development. vol.13, n.3, 1985.

POWELL, W.W. \& DI MAGGIO, P.J.: "The iron cage revisited: institutional isomorphism and collective rationality in organizational fields". In: POWELL, W. W. \& DI MAGGIO, P.J.: The new institutionalism in organizational analysis. p.63-82, University of Chicago Press, 1991. 
RILEY JR, J.W. \& RILEY, M.W.: "A comunicação de massa e o sistema social". In: COHN, G.: Comunicação e indústria cultural. p.118-154, Companhia Editora Nacional e Editora da USP, São Paulo, 1971.

SATOSHI, K.: Japão: a outra face do milagre. Brasiliense, São Paulo, 1985.

SCHEIN, E.: Seminário-diálogo com Edgar Schein sobre cultura organizacional. AMANA, (mimeo).

SILVA, E.B.: Refazendo a fábrica fordista. Hucitec, São Paulo,1991.

SULLIVAN, L.P.: "The seven stages in Company Wide Quality Control". In: Quality Progress. p.77-83, May 1986.

VARGAS, N.: "Gênese e difusão do taylorismo no Brasil". In: Ciências Sociais Hoje. p.155-189, 1985.

WEBER, M.: "Burocracia". In: WEBER, M.: Ensaios de sociologia. Zahar, Rio de Janeiro, 1974.

\section{DIFFUSION PROCESS AND TQC}

ABSTRACT - During the last decade, the concepts of so-called Japanese practices relating to production organization, labour-management relations and inter-firm relations, have spread widely to the USA, to European countries and to Brazil. The purpose of this article is to seek a better understanding of the features of the diffusion process of the TQC metodology

Key-words: diffusion process, TQC, institutionalization 